\title{
Effects of Geometrical Difference of Unsaturated Aliphatic Polyesters on Their Biodegradability III. Cross Effects of Molecular Weight and Geometric Structure of Poly(ethylene maleate/fumarate) and Its Model Compounds
}

\author{
Shigenobu TAKENOUCHI, Akinori TAKASU, Yoshihito INAI, and Tadamichi HIRABAYASHI ${ }^{\dagger}$ \\ Department of Environmental Technology and Urban Planning, Graduate School of Engineering, \\ Nagoya Institute of Technology, Gokiso-cho, Showa-ku, Nagoya 466-8555, Japan
}

(Received July 1, 2002; Accepted October 22, 2002)

\begin{abstract}
Unsaturated polyesters, P1a and P2a, having different molecular weight were synthesized by solution polycondensation of maleic anhydride (MAn) with ethylene glycol (EG). Furthermore, unsaturated polyesters, poly(ethylene maleate/fumarate) (P1b-e and P2b-e), which have various ratios of different $Z$-/E-configuration at the $\mathrm{C}=\mathrm{C}$ double bond were readily delivered from P1a and P2a, respectively, in 1,2-dichloroethane by using morpholine as a catalyst for isomerization. In order to discuss separately the effects of molecular weight of the samples on their biodegradability from the effects due to configuration of $\mathrm{C}=\mathrm{C}$ double bond, several $Z$ - or $E$-rich oligomeric model compounds having methyl esters as the terminal groups were prepared. The biodegradability of these polyester samples and oligomeric model compounds was evaluated from biochemical oxygen demand (BOD) values in the presence of an activated sludge. As the number-average molecular weight of both oligomeric model compounds and unsaturated polyesters was higher, their biodegradability was lowered by introducing $\mathrm{C}=\mathrm{C}$ double bond, especially, by that of $Z$-configuration. KEY WORDS Biodegradability / Unsaturated Polyester / Geometrical Isomer / Polycondensation /

Maleic Anhydride / Ethylene Glycol /
\end{abstract}

Synthetic polymeric materials have provided many advantages in our daily life for the last century, and become one of the most important materials. When once synthetic polymeric materials are disposed, however, those often caused serious environmental problems. Thus biodegradable polymers which were completely decomposed to $\mathrm{CO}_{2}$ and $\mathrm{H}_{2} \mathrm{O}$ in nature have received much attention in recent years as one of the answers to solve the problems. In fact, biodegradable polymers, especially aliphatic polyesters, have been widely investigated by many scientists in the world.

In spite of a large number of studies on biodegradability of polyesters, little attention has been given to unsaturated polyesters. ${ }^{1-7}$ Tokiwa and Suzuki reported that a few unsaturated polyesters containing 2-butenediol unit could be hydrolyzed by lipase. ${ }^{1}$ On the other hand, slightly cross-linked unsaturated polyesters, poly(hexamethylene fumarate) and poly(cis-2-butene fumarate), were hardly hydrolyzed by lipase.

A carbon-carbon double bond in unsaturated polyesters has two geometrical isomers ( $Z$ - and $E$ configuration) and such difference should affect their biodegradability depending on the substrate specificity of enzyme. In controlling the biodegradation rate of polyester, it must be useful to make geometrical effects clear. In our previous paper, 6,7 it was shown that in comparison with saturated polyesters, the ef-

${ }^{\dagger}$ To whom correspondence should be addressed . ficient degradation was prevented by introducing $Z$ configuration of $\mathrm{C}=\mathrm{C}$ double bond in the polyesters but introducing $E$-configuration did not do so remarkably. In addition to biochemical oxygen demand (BOD) measurement of polymer samples, dimethyl esters derived from the corresponding acids, maleic and fumaric acid, were measured. It was revealed that the simplest dimethyl esters are essentially subject to biodegradation even though it contains $\mathrm{C}=\mathrm{C}$ double bond. As the chain length of polyester having the double bond was longer, its biodegradability seemed to become lower. The biodegradation rate of unsaturated polyesters might be influenced by chain length of the polyesters as well as molar fractions of $Z-/ E$ configuration at $\mathrm{C}=\mathrm{C}$ double bond. Polymer samples in our previous works, oligomeric components less than about 1000 of their molecular weights were removed during purification by reprecipitation. It was very important for the present work to ensure the variety of samples in an oligomer region, otherwise we had only dimethyl maleate (or fumarate) as a model compound. Making a comparison between the polymers with only dimethyl maleate (or fumarate) did not give so fruitful information. Therefore we have been required to improve a preparative method for such oligomeric samples instead of polymerization route.

In this paper, in order to make clarify the effects of chain length of the unsaturated polyesters on their biodegradability, $Z$-rich oligomeric model compounds 
Z1-4 with different chain length were prepared from maleic anhydride (MAn) with ethylene glycol (EG). Furthermore, $E$-rich oligomeric model compounds $\boldsymbol{E} 1$ 4 were prepared through isomerization of the model compounds $\boldsymbol{Z 1 - 4}$ in 1,2-dichloroethane (DCE) by using morpholine (Mor) as a catalyst. ${ }^{7,8}$ Unsaturated polyesters P1a and P2a were synthesized by solution polycondensation of MAn with EG in the presence of $p$-toluenesulfonic acid $(p-\mathrm{TsOH})$ as a catalyst. Unsaturated polyesters P1a $\left(M_{\mathrm{n}}=1.3 \times 10^{3}\right)$ and P2a $\left(M_{\mathrm{n}}=3.5 \times 10^{3}\right)$ were also isomerized to give the polyesters P1b-e and $\mathbf{P 2 b}$-e which have a various ratios of different $Z$ - $/ E$-configuration at the $\mathrm{C}=\mathrm{C}$ double bond in a similar manner as preparation of oligomeric model compounds. The biodegradability of oligomeric model compounds and polyesters was evaluated from BOD values in an activated sludge. Thus, we would be able to discuss separately the effects of a chain length of unsaturated polyesters on their biodegradability from that due to configuration at $\mathrm{C}=\mathrm{C}$ double bond.

\section{EXPERIMENTAL}

\section{Materials}

Maleic anhydride (MAn), maleic acid (MA), fumaric acid (FA), ethylene glycol (EG), $p$-toluenesulfonic acid $(p$-TsOH), and morpholine (Mor) were purchased from Nacalai Tesque, Inc., Kyoto, Japan. MAn was purified by recrystallization from chloroform. EG, toluene (Tol), 1,2-dichloroethane (DCE), and Mor were purified by distillation according to conventional methods before use. For generation of diazomethane, a mixture of $100 \mathrm{~mL}$ of diethyl ether and $30 \mathrm{~mL}$ of $40 \%$ aqueous potassium hydroxide in a long glass tube was cooled to keep under $0^{\circ} \mathrm{C}, 10 \mathrm{~g}$ of powdered nitrosomethylurea was added in portions with shaking, and the yellow diazomethane in diethyl ether was separated by decantation. Nitrosomethylurea is synthesized from methylamine hydrochloride, urea, and sodium nitrite. ${ }^{9}$

\section{Measurement}

FT-IR spectra were recorded for film samples cast on $\mathrm{KBr}$ disk from chloroform solutions, using a JASCO FT/IR-430 spectrometer. ${ }^{1} \mathrm{H}$ and ${ }^{13} \mathrm{C}$ NMR spectra were recorded in $\mathrm{CDCl}_{3}$ at $27^{\circ} \mathrm{C}$ using a Bruker DPX$200 \mathrm{MHz}$ spectrometer. All of the chemical shifts were expressed as $\delta$ downfield from tetramethylsilane (TMS). The number-average molecular weight $\left(M_{\mathrm{n}}\right)$ and polydispersity index $\left(M_{\mathrm{w}} / M_{\mathrm{n}}\right)$ of polymers were determined at $40^{\circ} \mathrm{C}$ by gel permeation chromatography (GPC) calibrated with polystyrene standards using a system of Tosoh HLC-8020 equipped with a Tosoh RI-8020 detector and Tosoh G2000-HXL, G3000-HXL, G4000-
HXL, and G5000-HXL columns. Tetrahydrofuran was used as an eluent. Glass transition temperature $\left(T_{\mathrm{g}}\right)$ of the samples were determined by differential scanning calorimetry (DSC) using a Seiko Instrument DSC 210 from -100 to $120^{\circ} \mathrm{C}$ at a heating rate of $10^{\circ} \mathrm{C} \mathrm{min}^{-1}$.

\section{Synthesis of Z-rich Oligomeric Model Compounds}

MAn $(2.45 \mathrm{~g}, 25 \mathrm{mmol})$ was placed into a $50 \mathrm{~mL}$ round-bottomed flask equipped with a magnetic stirrer and a nitrogen gas inlet. The flask was immediately immersed in an oil bath and heated up to $120^{\circ} \mathrm{C}$. After MAn had been melted, EG $(1.55 \mathrm{~g}, 25 \mathrm{mmol})$ was added, and the mixture began first step reaction at $120^{\circ} \mathrm{C}$. Water produced during the first step reaction was removed under a reduced pressure $(0.2 \mathrm{mmHg})$. After prescribed time $(6-24 \mathrm{~h})$, excess MAn $(22.06 \mathrm{~g}$, $225 \mathrm{mmol}$ ) was added and allowed to react moreover $3 \mathrm{~h}$ at nitrogen atmosphere as second step reaction. In the case of $\boldsymbol{Z 1}$, all MAn $(24.52 \mathrm{~g}, 250 \mathrm{mmol})$ was added before second step reaction. After cooling down to room temperature, the mixture was diluted with $\mathrm{CHCl}_{3}$, and added dropwise cold solution of diazomethane in diethyl ether. The organic layer was washed with $5 \% \mathrm{NaHCO}_{3}$ and dried over $\mathrm{MgSO}_{4}$. Evaporation of solvent gave $Z$-rich model compounds: Yield; $1.21 \mathrm{~g}$ (16.9\%), for model compound $\boldsymbol{Z 1}$, the others $\boldsymbol{Z 2}-\boldsymbol{Z 4}$ are $1.01 \mathrm{~g}, 0.86 \mathrm{~g}$, and $1.32 \mathrm{~g}$, respectively. IR of $\boldsymbol{Z} \mathbf{1}$ $\left(\mathrm{KBr}\right.$ disk, cm $\left.{ }^{-1}\right): 2956\left[v_{\mathrm{C}-\mathrm{H}}\right], 1730\left[v_{\mathrm{C}=\mathrm{O}}(\right.$ ester $\left.)\right]$, $1643\left[v_{\mathrm{C}=\mathrm{C}}\right]$, and $1160\left[v_{\mathrm{C}-\mathrm{O}-\mathrm{C}}(\right.$ ester) $] .{ }^{1} \mathrm{H}$ NMR of

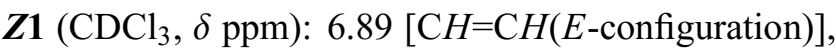
$6.29\left[\mathrm{CH}=\mathrm{CH}\right.$ (Z-configuration)], $4.46\left[\mathrm{OCH}_{2} \mathrm{CH}_{2} \mathrm{O}\right]$, and $3.80\left[\mathrm{COOCH}_{3}\right] .{ }^{13} \mathrm{C}$ NMR of $\boldsymbol{Z 1}\left(\mathrm{CDCl}_{3}\right.$, $\delta$ ppm): $165.4 \quad\left[\mathrm{CH}=\mathrm{CHCOOCH} \mathrm{CH}_{2}-\right], \quad 164.8$ $\left[\mathrm{CH}=\mathrm{CHCOOCH}_{3}\right], \quad 133.8 \quad\left[\mathrm{CH}=\mathrm{CHCOOCH}_{2} \mathrm{CH}_{2}-\right.$ (E-configuration) $], \quad 133.0 \quad\left[\mathrm{CH}=\mathrm{CHCOOCH}_{3} \quad(E-\right.$ configuration) $], \quad 130.1 \quad\left[\mathrm{CH}=\mathrm{CHCOOCH}_{2} \mathrm{CH}_{2}-\right.$ (Z-configuration) $], \quad 129.3 \quad\left[\mathrm{CH}=\mathrm{CHCOOCH}_{3} \quad(Z-\right.$ configuration)], $62.5 \quad\left[\mathrm{OCH}_{2} \mathrm{CH}_{2} \mathrm{O}\right]$, and 52.1 $\left[\mathrm{COOCH}_{3}\right]$. Z $Z / E$-configuration molar ratio of $\boldsymbol{Z 1}$ was $93 / 7$, the others $\boldsymbol{Z 2}-\mathbf{4}$ are in Table I, determined by the intensity of ratio of peak $b / a$ shown in Figure 1 a.

Table I. Characteristics of $Z$-rich model compounds (Z1-4)

\begin{tabular}{cccccc}
\hline $\begin{array}{c}\text { Model compound Reaction time } \\
Z \text {-series }\end{array}$ & \multicolumn{1}{c}{$\mathrm{h})$} & $Z / E^{\mathrm{b}}$ & $\begin{array}{c}M_{\mathrm{n}}^{\mathrm{c}} \\
\times 10^{-2}\end{array}$ & $M_{\mathrm{w}} / M_{\mathrm{n}}{ }^{\mathrm{c}} \begin{array}{c}T_{\mathrm{g}}{ }^{\mathrm{d}} \\
\left({ }^{\circ} \mathrm{C}\right)\end{array}$ \\
\hline $\boldsymbol{Z 1}$ & $0+3$ & $93 / 7$ & 2.8 & 1.1 & -61.6 \\
$\boldsymbol{Z 2}$ & $6+3$ & $75 / 25$ & 5.7 & 1.8 & -56.0 \\
$\boldsymbol{Z 3}$ & $12+3$ & $76 / 24$ & 6.7 & 1.9 & -54.1 \\
$\boldsymbol{Z 4}$ & $24+3$ & $67 / 33$ & 10.4 & 2.0 & -53.6 \\
\hline
\end{tabular}

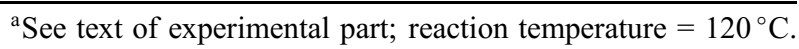
${ }^{\mathrm{b}}$ Molar ratio of $Z$ - and $E$-conformation unit in polymer, determined by ${ }^{1} \mathrm{H}$ NMR. ${ }^{\mathrm{c}}$ Determined by GPC calculated by polystyrene standards; eluent, THF. ${ }^{\mathrm{d}}$ Determined by DSC; heating rate, $10^{\circ} \mathrm{C} \mathrm{min}^{-1}$. 

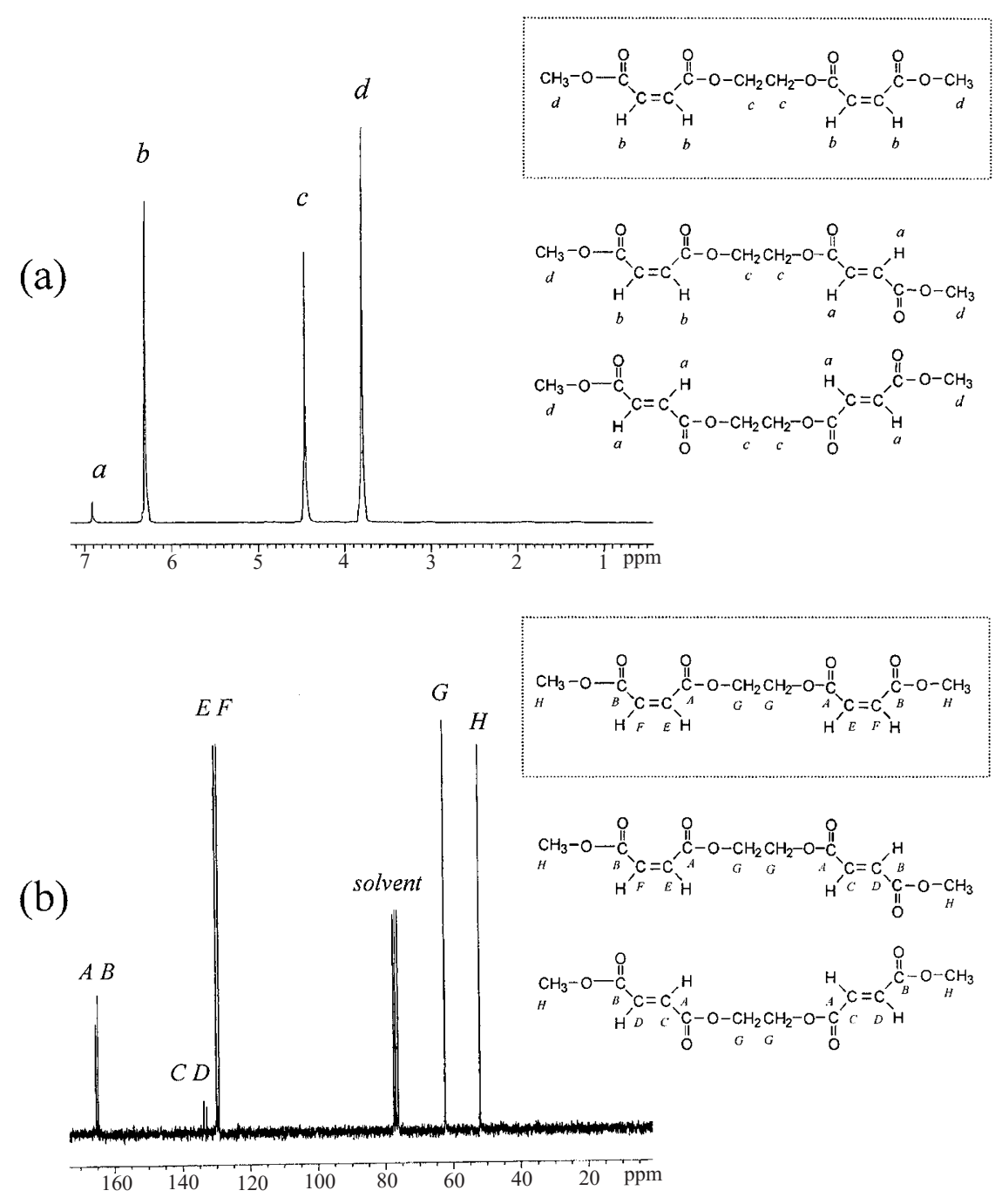

Figure 1. NMR spectra of $Z$-rich model compound $\boldsymbol{Z 1}$ in $\mathrm{CDCl}_{3}$ at $27{ }^{\circ} \mathrm{C}$; (a) ${ }^{1} \mathrm{H} \mathrm{NMR}$, (b) ${ }^{13} \mathrm{C} \mathrm{NMR}$.

\section{Isomerization Reaction of Z-rich Oligomeric Model Compounds}

A typical experimental procedure is as follows. Zrich model compounds $\boldsymbol{Z 1}(0.26 \mathrm{~g}, 1.0 \mathrm{mmol})$ was placed into a $10 \mathrm{~mL}$ round-bottomed flask equipped with reflux condenser, dissolved completely in $2.0 \mathrm{~mL}$ of DCE at room temperature under the nitrogen atmosphere. After Mor $(0.01 \mathrm{~g}, 0.1 \mathrm{mmol})$ had been added, the flask was immersed in an oil bath and immediately heated up to $80^{\circ} \mathrm{C}$. The mixture was stirred by magnetic stirrer at $80^{\circ} \mathrm{C}$ for $120 \mathrm{~min}$. After cooling down to room temperature, the mixture was diluted with $\mathrm{CHCl}_{3}$, and washed with water three times. The organic layer was dried in vacuo at room temperature to give $E$-rich model compounds E1: Yield; $0.177 \mathrm{~g}, 68.5 \%$, for the model compound $\boldsymbol{E 1}$, the others $\boldsymbol{E 2}-\boldsymbol{E} \mathbf{4}$ are in Table II. IR of $\boldsymbol{E} \mathbf{1}(\mathrm{KBr}$ disk, $\mathrm{cm}^{-1}$ ): $2963\left[v_{\mathrm{C}-\mathrm{H}}\right], 1719$ [ $v_{\mathrm{C}=\mathrm{O}}$ (ester)], 1647 $\left[v_{\mathrm{C}=\mathrm{C}}\right]$, and $1153\left[v_{\mathrm{C}-\mathrm{O}-\mathrm{C}}(\right.$ ester $\left.)\right] .{ }^{1} \mathrm{H}$ NMR of $\boldsymbol{E} \mathbf{1}$ $\left(\mathrm{CDCl}_{3}, \delta \mathrm{ppm}\right): 6.88[\mathrm{CH}=\mathrm{C} H(E$-configuration $)]$,
Table II. Isomerization reaction of $\boldsymbol{Z 1 - 4}$ to $E$-rich model compounds $(\boldsymbol{E} 1-4)$ in the presence of Mor ${ }^{\mathrm{a}}$

\begin{tabular}{cccccc}
\hline $\begin{array}{c}\text { Model compound } \\
E \text {-series }\end{array}$ & $\begin{array}{c}\text { Yield } \\
\mathrm{g}(\%)\end{array}$ & $Z / E^{\mathrm{b}}$ & $\begin{array}{c}M_{\mathrm{n}}{ }^{\mathrm{c}} \\
\times 10^{-2}\end{array}$ & $M_{\mathrm{w}} / M_{\mathrm{n}}{ }^{\mathrm{c}}$ & $\begin{array}{c}T_{\mathrm{g}}{ }^{\mathrm{d}} \\
\left({ }^{\circ} \mathrm{C}\right)\end{array}$ \\
\hline $\boldsymbol{E 1}$ & $0.18(68.5)$ & $1 / 99$ & 2.8 & 1.1 & -41.6 \\
$\boldsymbol{E 2}$ & $0.14(55.5)$ & $2 / 98$ & 6.0 & 1.7 & -37.5 \\
$\boldsymbol{E 3}$ & $0.17(65.2)$ & $1 / 99$ & 7.4 & 1.7 & -33.7 \\
$\boldsymbol{E 4}$ & $0.15(58.1)$ & $1 / 99$ & 10.6 & 1.9 & -29.9 \\
\hline
\end{tabular}

${ }^{\mathrm{a}}$ Z1-4 = 0.26 g $(1.0 \mathrm{mmol}) ;$ Mor $=0.01 \mathrm{~g}(0.1 \mathrm{mmol}) ; \mathrm{DCE}=$ $2.0 \mathrm{~mL}$; reaction temperature $=80^{\circ} \mathrm{C}$; reaction time $=120 \mathrm{~min}$. ${ }^{\mathrm{b}}$ Molar ratio of $Z$ - and $E$-conformation unit in polymer, determined by ${ }^{1} \mathrm{H}$ NMR. $\quad{ }^{\mathrm{c}}$ Determined by GPC calculated by polystyrene standards; eluent, THF. ${ }^{\mathrm{d}}$ Determined by DSC; heating rate, $10^{\circ} \mathrm{C} \mathrm{min}^{-1}$.

$6.28\left[\mathrm{CH}=\mathrm{CH}(\mathrm{Z}\right.$-configuration) $], 4.47\left[\mathrm{OCH}_{2} \mathrm{CH}_{2} \mathrm{O}\right]$, and $3.82\left[\mathrm{COOCH}_{3}\right] .{ }^{13} \mathrm{C}$ NMR of $\boldsymbol{E 1}\left(\mathrm{CDCl}_{3}\right.$, $\delta$ ppm): $165.1 \quad\left[\mathrm{CH}=\mathrm{CHCOOCH}_{2} \mathrm{CH}_{2}-\right], \quad 164.5$ $\left[\mathrm{CH}=\mathrm{CHCOOCH}_{3}\right], \quad 134.0 \quad\left[\mathrm{CH}=\mathrm{CHCOOCH}_{2} \mathrm{CH}_{2}-\right.$ (E-configuration)], $132.9\left[\mathrm{CH}=\mathrm{CHCOOCH}_{3}(E\right.$-configuration)], $62.7\left[\mathrm{OCH}_{2} \mathrm{CH}_{2} \mathrm{O}\right]$, and $52.3\left[\mathrm{COOCH}_{3}\right]$. $Z$-/E-configuration molar ratio of $\boldsymbol{E} \mathbf{1}$ was $1 / 99$, the others $\boldsymbol{E 2 - 4}$ are in Table II. 
Table III. Solution polycondensation of MAn with EG catalyzed with $p$-TsOH ${ }^{\mathrm{a}}$

\begin{tabular}{ccccccc}
\hline Polyester & $\begin{array}{c}p \text {-TsOH } \\
(\mathrm{mol} \%)\end{array}$ & $\begin{array}{c}\text { Yield } \\
(\%)\end{array}$ & $Z / E^{\mathrm{b}}$ & $\begin{array}{c}M_{\mathrm{n}}{ }^{\mathrm{c}} \\
\times 10^{-3}\end{array}$ & $M_{\mathrm{w}} / M_{\mathrm{n}}{ }^{\mathrm{c}}$ & $m_{1} / m_{2}{ }^{\mathrm{d}}$ \\
\hline P1a & 0.1 & 79.8 & $78 / 22$ & 1.3 & 1.5 & $44 / 56$ \\
P2a & 1.0 & 87.6 & $81 / 19$ & 3.5 & 1.5 & $46 / 54$ \\
\hline
\end{tabular}

${ }^{\mathrm{a}}[\mathrm{MAn}]_{0}=[\mathrm{EG}]_{0}=100.0 \mathrm{mmol} ;[\mathrm{Tol}]_{0}=50 \mathrm{~mL}$; reaction temp $=130{ }^{\circ} \mathrm{C}$; reaction time $=24 \mathrm{~h}$. ${ }^{\mathrm{b}}$ Molar ratio of $Z$ - and $E$-conformation unit in polymer, determined by ${ }^{1} \mathrm{H}$ NMR. ${ }^{c}$ Determined by GPC calculated by polystyrene standards; eluent, THF. ${ }^{\mathrm{d}}$ Molar ratio of MAn $\left(m_{1}\right)$ unit to EG $\left(m_{2}\right)$ unit in polymer, determined by ${ }^{1} \mathrm{H}$ NMR.

Table IV. Isomerization reaction from $Z$ - to $E$-configuration for polyester P1a and P2a in the presence of Mor ${ }^{\mathrm{a}}$

\begin{tabular}{ccccccc}
\hline Polyester & $\begin{array}{c}\text { Reaction Time } \\
(\min )\end{array}$ & $\begin{array}{c}\text { Yield } \\
\mathrm{g}(\%)\end{array}$ & $Z / E^{\mathrm{d}}$ & $\begin{array}{c}M_{\mathrm{n}}{ }^{\mathrm{e}} \\
\times 10^{-3}\end{array}$ & $M_{\mathrm{w}} / M_{\mathrm{n}}{ }^{\mathrm{e}}$ & $\begin{array}{c}T_{\mathrm{g}}{ }^{\mathrm{f}} \\
\left({ }^{\circ} \mathrm{C}\right)\end{array}$ \\
\hline P1a & - & - & $78 / 22$ & 1.3 & 1.5 & -38.7 \\
$\mathbf{P 1 b}^{\mathrm{b}}$ & 10 & $0.59(82.5)$ & $49 / 51$ & 1.4 & 1.4 & -18.5 \\
$\mathbf{P 1 c}^{\mathrm{b}}$ & 30 & $0.59(83.4)$ & $38 / 62$ & 1.4 & 1.4 & -14.0 \\
$\mathbf{P 1 d}^{\mathrm{b}}$ & 60 & $0.53(74.1)$ & $18 / 82$ & 1.5 & 1.5 & -10.2 \\
P1e $^{\mathrm{b}}$ & 120 & $0.50(71.0)$ & $5 / 95$ & 1.5 & 1.5 & -0.4 \\
$\mathbf{P 2 a}$ & - & - & $81 / 19$ & 3.5 & 1.5 & -17.5 \\
$\mathbf{P 2} \mathbf{b}^{\mathrm{c}}$ & 10 & $0.53(74.9)$ & $50 / 50$ & 3.7 & 1.6 & -14.7 \\
$\mathbf{P 2 c}^{\mathrm{c}}$ & 30 & $0.56(79.3)$ & $29 / 71$ & 4.0 & 1.6 & -9.7 \\
$\mathbf{P 2 d}^{\mathrm{c}}$ & 60 & $0.46(64.9)$ & $12 / 88$ & 4.2 & 1.6 & -7.0 \\
$\mathbf{P 2 e}^{\mathrm{c}}$ & 120 & $0.51(72.3)$ & $9 / 91$ & 4.1 & 1.6 & -6.3 \\
\hline
\end{tabular}

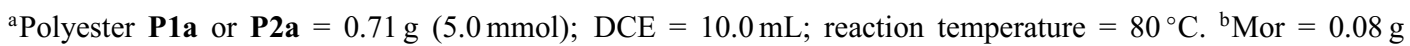
$(1.0 \mathrm{mmol}) .{ }^{\mathrm{c}} \mathrm{Mor}=0.04 \mathrm{~g}(0.5 \mathrm{mmol})$. ${ }^{\mathrm{d}} \mathrm{Molar}$ ratio of $Z$ - and $E$-conformation unit in polymer, determined by ${ }^{1} \mathrm{H}$ NMR. ${ }^{\mathrm{e}}$ Determined by GPC calculated by polystyrene standards; eluent, THF. ${ }^{\mathrm{f}}$ Determined by DSC; heating rate, $10^{\circ} \mathrm{C} \mathrm{min}^{-1}$.

\section{Polycondensation of Maleic Anhydride with Ethylene Glycol}

Unsaturated polyesters P1a and P2a were prepared by a solution polycondensation method. ${ }^{10-13}$ A typical experimental procedure is as follows. MAn $(9.81 \mathrm{~g}$, $100.0 \mathrm{mmol})$, EG $(6.21 \mathrm{~g}, 100.0 \mathrm{mmol})$, Tol $(50.0 \mathrm{~mL})$, and the required amount of $p-\mathrm{TsOH}$ as a catalyst were placed into a $100 \mathrm{~mL}$ round-bottomed flask equipped with a Dean-Stark trap with a reflux condenser, and a nitrogen gas inlet. The reaction mixture was refluxed at $130^{\circ} \mathrm{C}$ for $24 \mathrm{~h}$ under a stream of nitrogen, stirring magnetically. After cooling, the mixture was diluted with $\mathrm{CHCl}_{3}$, and then the organic solution was poured into diethyl ether to obtain precipitate. After reprecipitation from $\mathrm{CHCl}_{3}$ solution into diethyl ether three times, the polymeric materials were collected and dried in vacuo at room temperature to give polyester P1a: Yield; $11.3 \mathrm{~g}(79.8 \%)$ for P1a and $12.5 \mathrm{~g}(87.6 \%)$ for P2a in Table III. IR of P1a (KBr disk, $\left.\mathrm{cm}^{-1}\right): 2961$ $\left[v_{\mathrm{C}-\mathrm{H}}\right], 1735\left[v_{\mathrm{C}=\mathrm{O}}\right.$ (ester) $], 1643\left[v_{\mathrm{C}=\mathrm{C}}\right]$, and 1162 [ $v_{\mathrm{C}-\mathrm{O}-\mathrm{C}}$ (ester)]. ${ }^{1} \mathrm{H}$ NMR of P1a $\left(\mathrm{CDCl}_{3}, \delta \mathrm{ppm}\right)$ : $6.89[\mathrm{CH}=\mathrm{C} H(E$-configuration $)], 6.31 \quad[\mathrm{CH}=\mathrm{CH}(Z$ configuration)], and $4.42\left[\mathrm{OCH}_{2} \mathrm{CH}_{2} \mathrm{O}\right] \cdot{ }^{13} \mathrm{C} \mathrm{NMR}$ of P1a $\left(\mathrm{CDCl}_{3}, \delta \mathrm{ppm}\right): 164.7[C \mathrm{O}], 133.5[C \mathrm{H}=C \mathrm{H}(E-$ configuration)], $129.8[\mathrm{CH}=\mathrm{CH}$ ( $Z$-configuration)], and $62.6\left[\mathrm{OCH}_{2} \mathrm{CH}_{2} \mathrm{O}\right]$. $\mathrm{Z} / \mathrm{E}$ ratio was found as $78 / 22$ for P1a and 81/19 for P2a, respectively.

\section{Isomerization Reaction of Polyesters P1a and P2a}

Isomerization reaction of polyesters P1a and P2a carried out in a similar manner to that of the model compounds described above. Polyesters P1b-e and P2b-e were purified by reprecipitation of $\mathrm{CHCl}_{3}$ solution into diethyl ether: Yield; $0.59 \mathrm{~g}, 82.5 \%$, for polyester P1b, the others are in Table IV. IR of P1b $\left(\mathrm{KBr}\right.$ disk, cm $\left.{ }^{-1}\right): 2959\left[v_{\mathrm{C}-\mathrm{H}}\right], 1725\left[v_{\mathrm{C}=\mathrm{O}}\right.$ (ester)], $1643\left[v_{\mathrm{C}=\mathrm{C}}\right]$, and $1158\left[v_{\mathrm{C}-\mathrm{O}-\mathrm{C}}(\right.$ ester $\left.)\right] .{ }^{1} \mathrm{H}$ NMR of P1b $\left(\mathrm{CDCl}_{3}, \delta \mathrm{ppm}\right): 6.89[\mathrm{C} H=\mathrm{C} H(E$-configuration)], 6.30 [CH=CH(Z-configuration)$)$, and 4.43 $\left[\mathrm{OCH}_{2} \mathrm{CH}_{2} \mathrm{O}\right] .{ }^{13} \mathrm{C}$ NMR of $\mathbf{P 1 b}\left(\mathrm{CDCl}_{3}, \delta \mathrm{ppm}\right)$ : $164.5[\mathrm{CO}], 133.6[\mathrm{CH}=\mathrm{CH}$ (E-configuration)], 129.9 $\left[\mathrm{CH}=\mathrm{CH}\right.$ (Z-configuration)], and $62.8\left[\mathrm{OCH}_{2} \mathrm{CH}_{2} \mathrm{O}\right]$. $Z / E$ ratio was summarized in Table IV.

\section{Biochemical Oxygen Demand Test}

Biochemical oxygen demand (BOD) value of the samples was determined by the oxygen consumption method according to the JIS K 6950 in aerobic at $25^{\circ} \mathrm{C}$, using a BOD tester (Model 200F, TAITEC Co., Koshigaya, Japan). The activated sludge was available from Municipal disposal plant in Nagoya. The incubation medium was composed of $\mathrm{K}_{2} \mathrm{HPO}_{4}$ (217.5), $\mathrm{KH}_{2} \mathrm{PO}_{4}$ (85.0), $\mathrm{Na}_{2} \mathrm{HPO}_{4} \cdot 2 \mathrm{H}_{2} \mathrm{O}$ (334.0), $\mathrm{NH}_{4} \mathrm{Cl}$ (5.0), $\quad \mathrm{CaCl}_{2} \cdot 2 \mathrm{H}_{2} \mathrm{O}$ (36.4), $\quad \mathrm{MgSO}_{4} \cdot 7 \mathrm{H}_{2} \mathrm{O}$ (22.5), $\mathrm{FeCl}_{3} \cdot 6 \mathrm{H}_{2} \mathrm{O}\left(0.25 \mathrm{mg} \mathrm{L}^{-1}\right)$, kept at $\mathrm{pH}=$ 


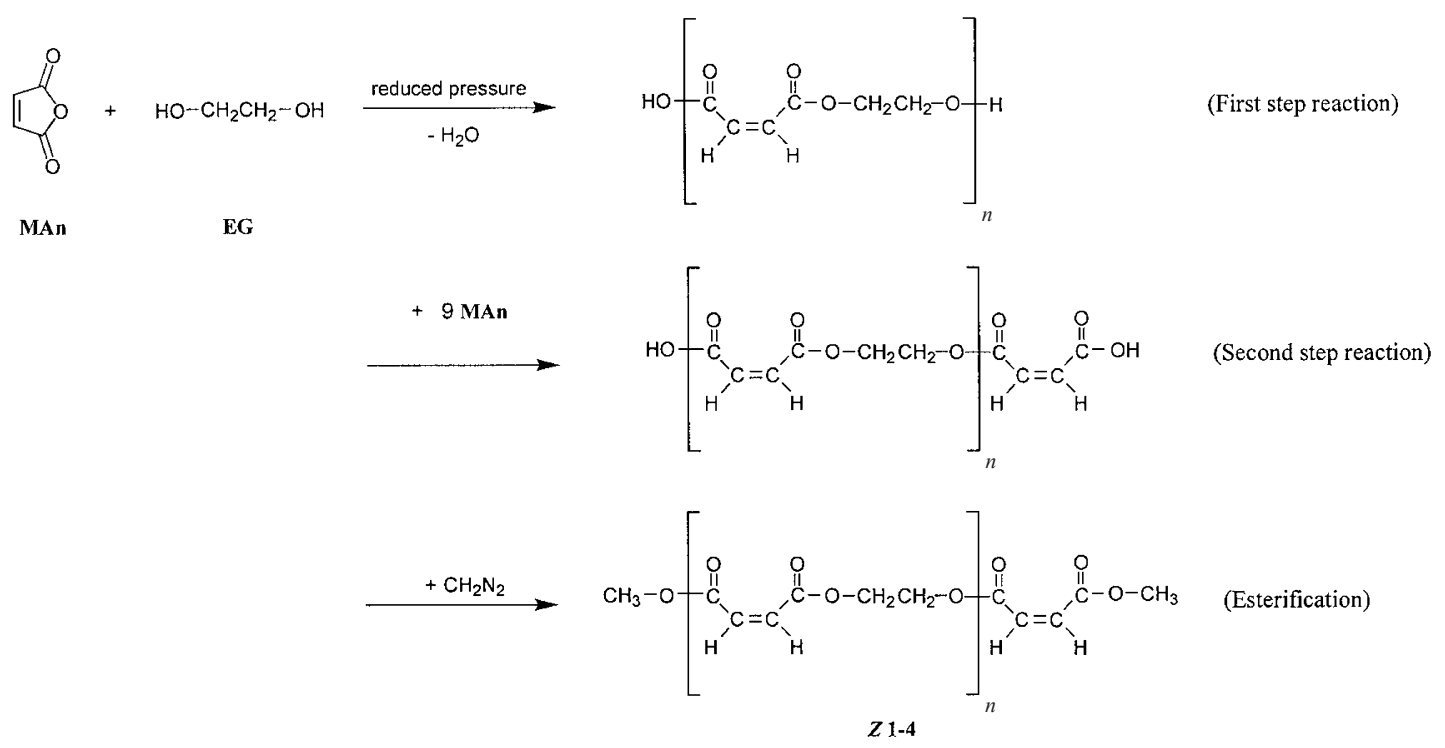

Scheme 1. Synthesis of $Z$-rich oligomeric model compounds (Z1-4).

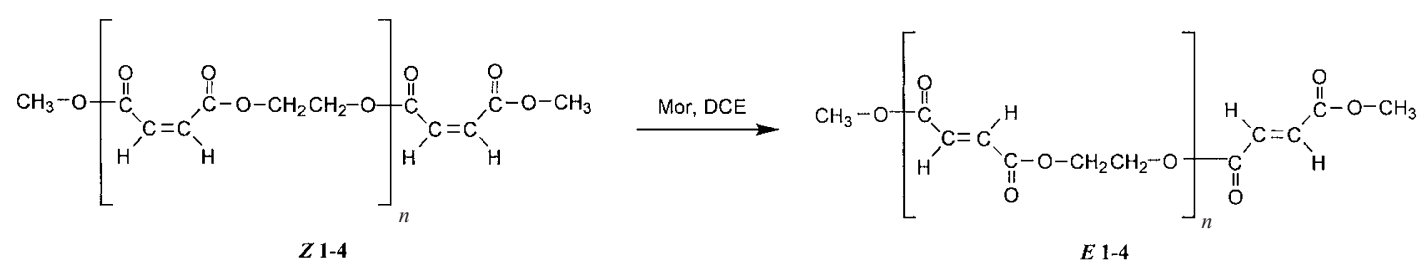

Scheme 2. Isomerization of $Z$-rich oligomeric model compounds (Z1-4).

$7.4 \pm 0.1$. Since polyester samples and oligomeric model compounds were viscous liquid at room temperature, each sample in chloroform solution was cast to film on bottom of the bottle in height of $2 \mathrm{~cm}$. Corresponding simplest monomer unit, MA, FA (powder), and EG (liquid) were added to bottom of the bottle as it is. The concentration of polymers in the incubation medium was $100 \mathrm{mg} \mathrm{L}^{-1}$.

\section{RESULTS AND DISCUSSION}

\section{Synthesis of Z-rich Oligomeric Model Compounds}

According to Scheme 1, Z-rich oligomeric model compounds $Z 1-4$ were prepared from MAn with EG at $120^{\circ} \mathrm{C}$. Melt polycondensation under reduce pressure was carried out at the first step reaction. As the first step reaction time became longer, the chain length of the oligomeric model compounds was also longer. At the second step reaction, excess MAn was subjected to react with terminal hydroxyl groups of oligomers. Almost end groups of the model compounds could be completely converted to carboxyl groups, judging from spectroscopic data after dealing with $\mathrm{CH}_{2} \mathrm{~N}_{2}$. After cooling, the reaction solution was diluted with $\mathrm{CHCl}_{3}$ and then cold solution of diazomethane in diethyl ether was added dropwise. Carboxyl end groups in the model compounds could be immediately changed to methyl ester groups at room temperature. In the synthesis of $Z$-rich oligomeric model compounds $\boldsymbol{Z} \mathbf{1 - 4}$, light-brown viscous sample showing no $T_{\mathrm{m}}$ was obtained (Table I).

The NMR spectra for $\boldsymbol{Z} 1$ are shown in Figure 1. $\boldsymbol{Z} \mathbf{1}$ was found to be dimethyl ester of almost single product consisted of $\mathrm{MAn} / \mathrm{EG}=2 / 1$. However the others $(\boldsymbol{Z} 2-$ 4) were mixtures of a few oligomeric ester compounds, which confirmed by GPC. Molecular weights of Z1-4 could be controlled in the region of the number-average molecular weight $\left(M_{\mathrm{n}}\right)$ from 2.8 to $10.4 \times 10^{2}$ by reaction time of the first step reaction. Although there were a few small peaks assigned to $E$-configuration at $\mathrm{C}=\mathrm{C}$ double bonds in the NMR spectra for $\boldsymbol{Z 1}$, but $\boldsymbol{Z 1}$ were mainly consisted of $Z, Z$-configuration compound. As the reaction time of the first step reaction was longer, isomerization from $Z$ - to $E$-configuration at unsaturated acid units occurred partially as a result of long heating.

\section{Isomerization Reaction of Z-rich Oligomeric Model Compounds}

It is well known that the $\mathrm{C}=\mathrm{C}$ double bond of $Z$ configuration can be more efficiently isomerized into $E$-configuration in the presence of amine compounds as a catalyst. ${ }^{7,8}$ Thus isomerization of $Z$-rich oligomeric model compounds $\boldsymbol{Z 1 - 4}$ was examined with Mor in DCE at $80^{\circ} \mathrm{C}$ (Scheme 2 and Figure 2). The NMR spectra for $\boldsymbol{E} 1$ are shown in Figure 2. The occurrence 

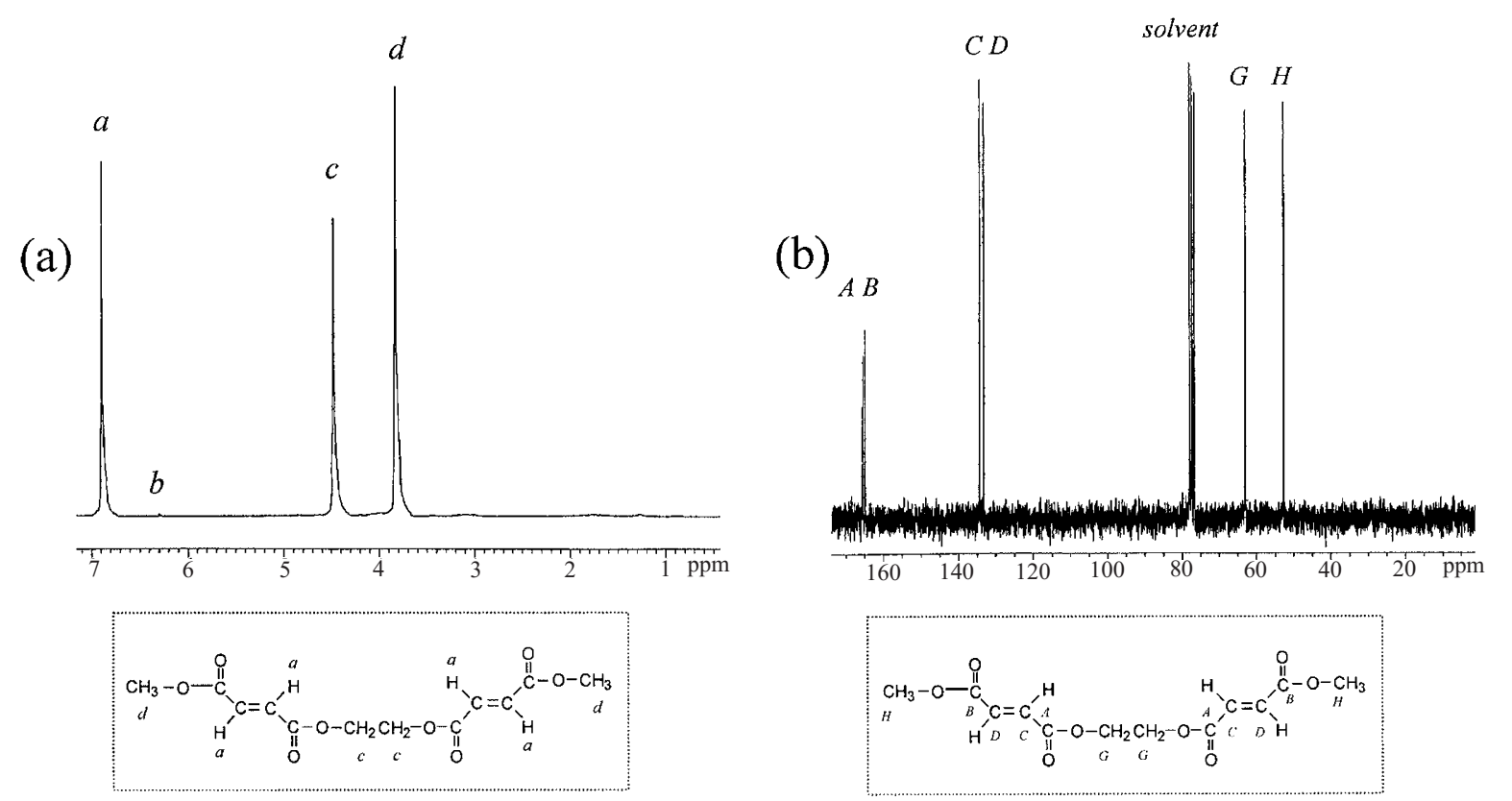

Figure 2. NMR spectra of $E$-rich model compound $\boldsymbol{E} 1$ in $\mathrm{CDCl}_{3}$ at $27{ }^{\circ} \mathrm{C}$; (a) ${ }^{1} \mathrm{H} \mathrm{NMR}$, (b) ${ }^{13} \mathrm{C} \mathrm{NMR}$.

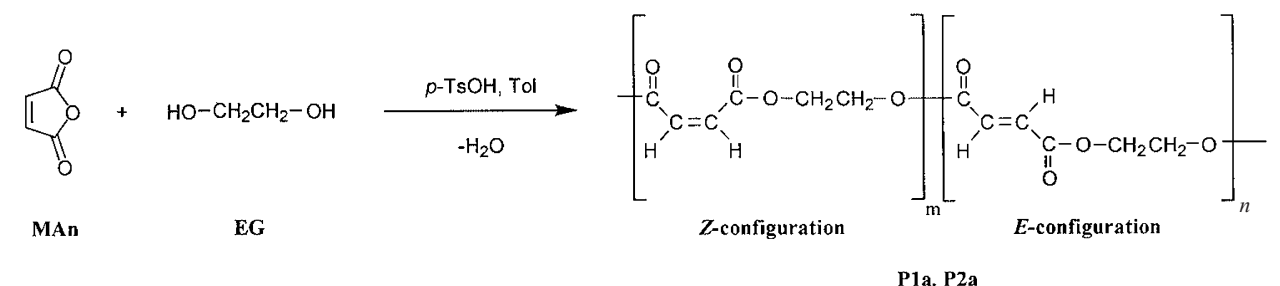

Scheme 3. Solution polycondensation of MAn with EG.

of isomerization from $Z$ - to $E$-configuration was clearly confirmed by disappearance of peak $b$ at about $6.3 \mathrm{ppm}$ in Figure 2a and peak $E$ and $F$ at about $130 \mathrm{ppm}$ in Figure $2 b$, which peaks are assigned to $\mathrm{CH}=\mathrm{CH}(Z$ configuration). The results are summarized in Table II, showing that highly $E$-rich oligomeric model compounds $E 1-4$ can be obtained without any remarkable change of molecular weight.

\section{Solution Polycondensation of Maleic Anhydride with Ethylene Glycol}

Soluble polyesters containing an unsaturated unit in organic solvents could not be achieved well through a melt polycondensation method because of gelation at the initial stage. Therefore solution polycondensation shown in Scheme 3 was employed to prepare unsaturated polyesters P1a and P2a. ${ }^{10-13}$ Table III shows the results of solution polycondensation of MAn with EG.

$M_{\mathrm{n}}$ of polyesters P1a and P2a was $1.3 \times 10^{3}$ and $3.5 \times 10^{3}$, respectively, depended on quantity of $p$ $\mathrm{TsOH}$. The unsaturated polyesters obtained by solution polycondensation were essentially a linear polymer, but their molecular weight could not be achieved to $M_{\mathrm{n}}>10^{4}$. To obtain polyester with higher molec- ular weight, the chain extension reaction of polymers with a titanium isopropoxide catalyst was also examined previously. ${ }^{14,15}$ However it resulted in serious gelation of the polymer rather than the chain extension. For the present, it is difficult to obtain the unsaturated polyesters with high molecular weight without cross-linking. Thus, oligomeric polyester samples were suited for the biodegradation tests in order to discuss the geometrical effects on biodegradability of unsaturated polyesters without negative effects due to crosslinking.

It is also well known that the $\mathrm{C}=\mathrm{C}$ double bonds of $Z$ configuration often isomerize into $E$-configuration during esterification of unsaturated anhydrides with diols in the presence of an acid catalyst. ${ }^{16-19}$ The molar ratio of $Z / E$ in polyesters P1a and P2a was $78 / 22$ and $81 / 19$, respectively. Since EG take place etherification with a stronger acid catalyst, formation of EG-EG linkage might not be removed completely in the course of the present polymerization. However, the composition ratio $m_{1} / m_{2}$ of P1a and P2a was nearly 1:1 composition and the content of ether units could be recognized as extremely low. 

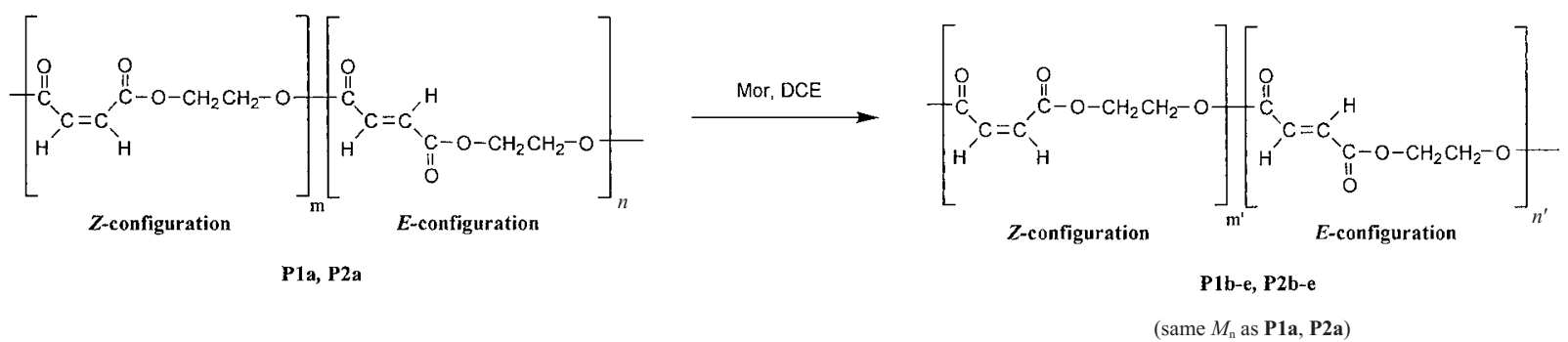

Scheme 4. Isomerization of polyesters P1a and P2a.

\section{Isomerization Reaction of Polyesters P1a and P2a}

Isomerization reaction from $Z$ - to $E$-configuration of polyesters P1a and P2a in DCE in the presence of Mor was also conducted (Scheme 4). The results are summarized in Table IV.

In comparison with $\mathbf{P 2 b}$-e, isomerization reaction of P1a required the twice amount of Mor catalyst in order to obtain highly $E$-rich polyesters. It may be a reason that there is strong interaction between Mor and terminal carboxyl groups. Thus two series of unsaturated polyesters, P1b-e and P2b-e having the same molecular weight but the different ratio of $Z$-/ $E$-configuration, could be optionally prepared from one original polymer P1a or P2a by controlling isomerization reaction time. The variety of $Z / E$ values was wide enough to investigate geometrical effects on biodegradability.

\section{Biochemical Oxygen Demand Test}

The biodegradability of unsaturated polyesters and oligomeric model compounds was evaluated from BOD/TOD (TOD: theoretical oxygen demand) values measured with a BOD tester using the oxygen consumption method for $30 \mathrm{~d}$ in the presence of activated sludge. In addition to these samples, BOD values of $\mathrm{MA}$ and FA, and EG were also measured taking into account the biodegradability of the smallest repeating unit.

Figure 3 shows the BOD/TOD values against reaction times. Low molecular weight compounds, MA, FA, and EG, began to degrade immediately and its BOD/TOD values reached over up to $70 \%$ after $10 \mathrm{~d}$. It could be concluded that monomer units supplied by hydrolysis of unsaturated polyesters are essentially biodegraded to $\mathrm{CO}_{2}$ and $\mathrm{H}_{2} \mathrm{O}$ by microorganism.

The biodegradability of oligomeric model compounds is shown in Figure 4. Even though two ester linkages were included in the same manner, the induction period of $\boldsymbol{Z} \mathbf{1}$ was longer than that of $\boldsymbol{E} \mathbf{1}$. This is a basic evidence for that a microorganism might to distinguish differences of configuration at $\mathrm{C}=\mathrm{C}$ double bond through hydrolysis and an aerobic metabolism process. In comparison with $\boldsymbol{Z} \mathbf{1}$ and $\boldsymbol{E} \mathbf{1}$, every oligomeric

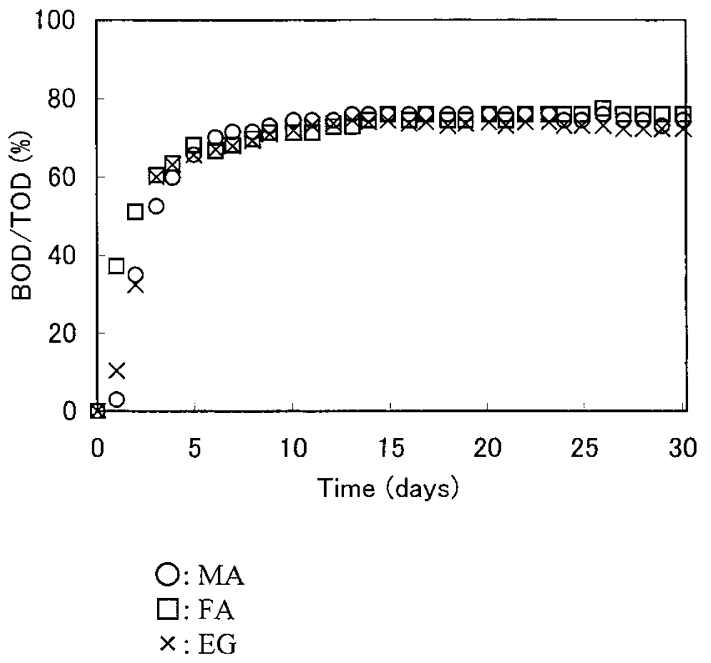

Figure 3. Biodegradability of MA, FA, and EG, corresponding to repeating units evaluated by biochemical oxygen demand (BOD) test.

model compounds, $\boldsymbol{Z 2}-\mathbf{4}$ and $\boldsymbol{E 2}-\mathbf{4}$, resulted in the lower biodegradability. These results would be reflected by the increase of hydrophobicity of the samples. The BOD/TOD values of $\boldsymbol{E} \mathbf{2}-\mathbf{4}$ were somewhat smaller than that of $\boldsymbol{Z 2 - 4}$ within $15 \mathrm{~d}$. It is worth noting that the $T_{\mathrm{g}}$ values of $\boldsymbol{E 2}-\mathbf{4}$ were more about $20^{\circ} \mathrm{C}$ higher than these of $\boldsymbol{Z 2 - 4}$. It may be reflected to the samples crystallinity on its biodegradability. Between $\boldsymbol{Z 2}$ and $\boldsymbol{E 2}$, as well as $\boldsymbol{Z 3}$ and $\boldsymbol{E 3}$, there were not significant effects of configuration on their biodegradability at $30 \mathrm{~d}$. On the other hand, the values of BOD/TOD after $30 \mathrm{~d}$ for $\boldsymbol{Z 4}$ and $\boldsymbol{E} \mathbf{4}$, which have rather high molecular weight, were $28.6 \%$ (Z4) and $41.9 \%(\boldsymbol{E} 4)$. This fact suggested that the preferential biodegradation with $E$-configuration could come out distinctly only when the molecular weight $\left(M_{\mathrm{n}}\right)$ of dimethylester model compounds was more than $c a .1000$.

Figure 5 shows the BOD/TOD values vs. time diagram for unsaturated polyesters P1a-e $\left(M_{\mathrm{n}}=1.3-\right.$ $\left.1.5 \times 10^{3}\right)$ and P2a-e $\left(M_{\mathrm{n}}=3.5-4.2 \times 10^{3}\right)$. In our previous paper, ${ }^{6}$ it have already been revealed that the biodegradation of the correspond saturated aliphatic polyester, namely poly(ethylene succinate) $\left[M_{\mathrm{n}}=\right.$ $\left.0.45-2.05 \times 10^{4}\right]$, could proceed immediately and did not so influenced by their molecular weight. In 
(a)

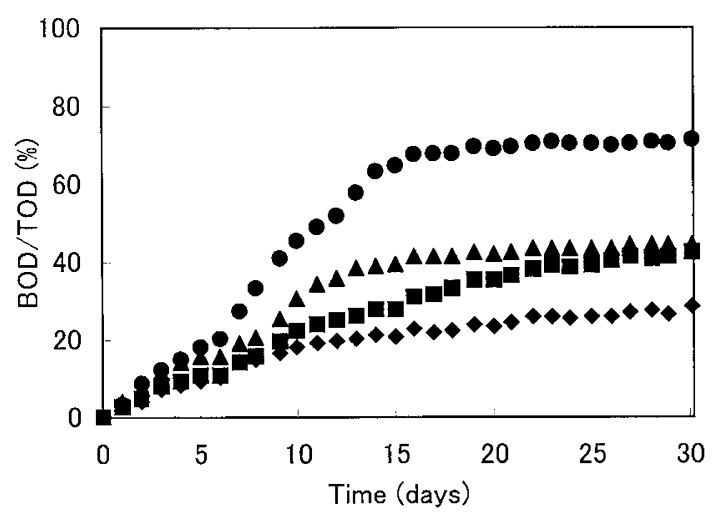

: $Z 1$

$\mathbf{A}: Z 2$

$\mathbf{\square}: Z 3$

$\checkmark: Z 4$

(b)

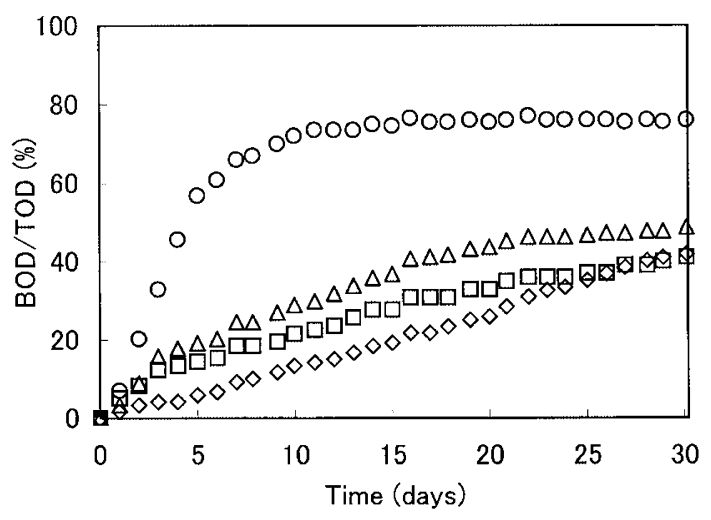

$\bigcirc: E \mathbf{1}$
$\triangle: E \mathbf{2}$
$\square: E \mathbf{3}$
$\diamond: E \mathbf{4}$

Figure 4. Biodegradability of oligomeric model compounds evaluated by BOD test; (a) Z-rich model compounds $Z \mathbf{Z 1 - 4}$, (b) $E$ rich model compounds $\boldsymbol{E} \mathbf{1 - 4}$.

comparison with the saturated polyesters, unsaturated polyesters P1a-e, which number average molecular weights were in range of $1.3-1.5 \times 10^{3}$, prevented their efficient biodegradation. It might be significantly influenced on their biodegradation that the flexibility of polymer main chain would decrease by introducing rigid $\mathrm{C}=\mathrm{C}$ double bonds. There was little difference among P1a-e on their BOD/TOD curves. It seemed to be difficult for $Z$-configuration $\mathrm{C}=\mathrm{C}$ bond to clarify the substrate specificity of enzyme through those limited conformational variety.

End groups of such polyester samples were consisted of $-\mathrm{COOH}$ or $-\mathrm{OH}$, that is, hydrophilicity was higher than the model compounds mentioned above. Generally speaking, hydrophilic compounds were preferred in hydrolysis by microorganism. The biodegradation of unsaturated polyesters P1a-e were differ from the case of the oligomeric model compounds ( $\boldsymbol{Z 4}$ and $\boldsymbol{E 4})$ even though they have the approximately same molecu- (a)

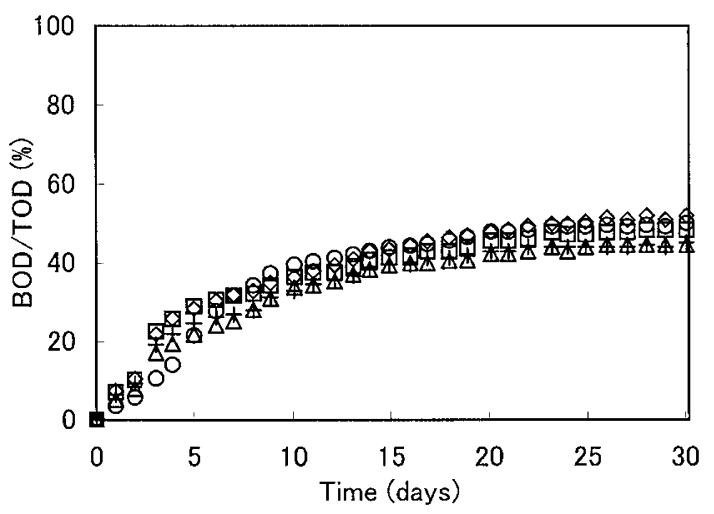

O: P1a $Z / E=78 / 22$

$\triangle:$ P1b $Z / E=49 / 51$

+: P1c $Z / E=38 / 62$

$\square:$ P1d $Z / E=18 / 82$

$\diamond:$ P1e $Z / E=5 / 91$

(b)

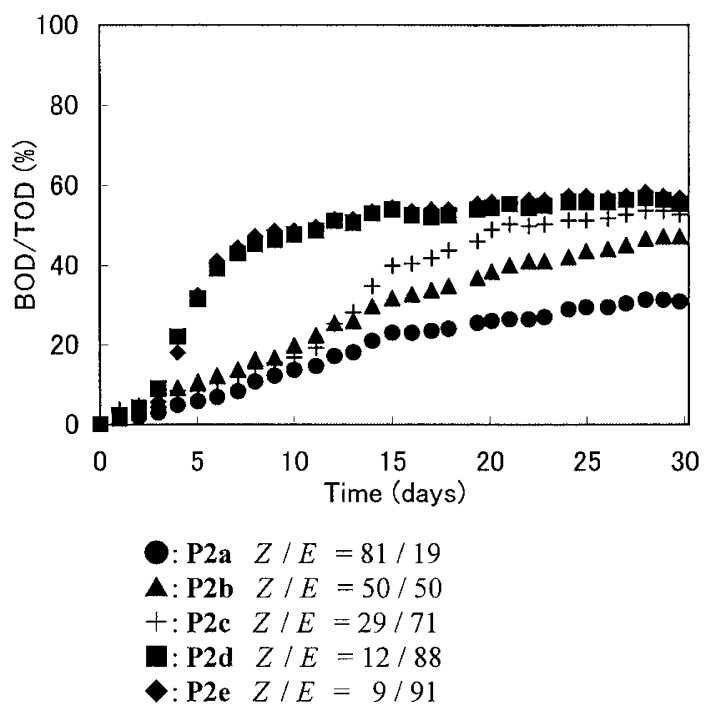

Figure 5. Biodegradability of polyesters prepared from MAn and EG evaluated by BOD test; (a) P1a-e, (b) P2a-e.

lar weight $\left(M_{\mathrm{n}}=1.0-1.1 \times 10^{3}\right)$. The BOD/TOD value of P2a was $30.9 \%$ after $30 \mathrm{~d}$, however, these values for P2b-e changed to much higher levels than that of P2a, as the proportion of $E$-configuration increased. This rate enhancement should be contributed by increasing of $E$-configuration fraction in the $\mathrm{C}=\mathrm{C}$ double bonds. Now, it is obvious fact that $Z$ - and $E$-configuration in the $\mathrm{C}=\mathrm{C}$ double bonds affected their biodegradability in the different manner, especially in the polyesters having relatively high molecular weight. In other words, the biodegradation rate might be controlled by the introduction of some $\mathrm{C}=\mathrm{C}$ double bond in chain of aliphatic polyester and furthermore adjusted finely depending on its $Z / E$ ratio.

\section{CONCLUSION}

Unsaturated aliphatic polyesters P1a $\left(M_{\mathrm{n}}=1.3 \times\right.$ $\left.10^{3}\right)$ and P2a $\left(M_{\mathrm{n}}=3.5 \times 10^{3}\right)$ were prepared from 
MAn and EG by the use of solution polycondensation method. In order to investigate geometrical effects as well as effects of molecular weight on biodegradability, polyesters P1b-e and P2b-e were derived from one original polymer P1a or P2a, respectively, by isomerization reaction from $Z$ - to $E$-configuration in DCE by using Mor. There was little difference concerning the biodegradability of P1a-e, suggesting that oligomeric polyesters with the molecular weight around 1300 could be degraded by microorganism irrespective of their geometrical structures. However, an effect of the molar ratio of $Z-/ E$-configuration at the $\mathrm{C}=\mathrm{C}$ double bonds could be found on the biodegradability of P2ae having much longer chain length than P1a-e. The biodegradability of $E$-configuration rich polyesters was clearly superior to $Z$-rich one with regard to biodegradability of P2a-e. When molecular weight $\left(M_{\mathrm{n}}\right)$ of oligomeric model compounds were more than $c a$. 1000, it can be recognized that the preferable biodegradability of $E$-configuration could come out clearly, even though the hydrophobicity of oligomeric model compounds influenced on their biodegradability in the different manner. Thus the effects of configuration of $\mathrm{C}=\mathrm{C}$ double bonds could be estimated separately from the effects due to their chain length.

\section{REFERENCES}

1. Y. Tokiwa and T. Suzuki, Nature, 270, 76 (1977).
2. N. Valiente, T. Lalot, M. Brigodiot, and E. Marechal, J. Polym. Sci., Part A: Polym. Chem., 35, 27 (1997).

3. N. Valiente, T. Lalot, M. Brigodiot, and E. Marechal, J. Polym. Sci., Part A: Polym. Chem., 35, 35 (1997).

4. H. Jin, D. Kim, B. Lee, M. Kim, I. Lee, H. Lee, and J. Yoon, J. Polym. Sci., Part B: Polym. Phys., 38, 2240 (2000).

5. A. Takasu, M. Ito, Y. Inai, T. Hirabayashi, and Y. Nishimura, Polym. J., 31, 961 (1999).

6. S. Takenouchi, A. Takasu, Y. Inai, and T. Hirabayashi, Polym. $J$, 33, 746 (2001).

7. S. Takenouchi, A. Takasu, Y. Inai, and T. Hirabayashi, Polym. J., 34, 36 (2002).

8. N. Toyoda, M. Yoshida, and T. Otsu, Polym. J., 15, 255 (1983).

9. F. Arndt, Organic Syntheses Col., 2, 461 (1943).

10. H. Batzer, H. Holtschmidt, F. Wiloth, and B. Mohr, Makromol. Chem., 7, 82 (1951).

11. H. Batzer and B. Mohr, Makromol. Chem., 8, 217 (1952).

12. C. Won, C. Chu, and J. D. Lee, J. Polym. Sci., Part A: Polym. Chem., 36, 2949 (1998).

13. C. Won, C. Chu, and J. D. Lee, Polymer, 39, 6677 (1998).

14. Y. Maeda, A. Nakayama, N. Kawasaki, K. Hayashi, S. Aiba, and N. Yamamoto, J. Environ. Polym. Degrad., 4, 225 (1996).

15. Y. Maeda, A. Nakayama, N. Kawasaki, K. Hayashi, S. Aiba, and N. Yamamoto, Polym. J., 29, 836 (1997).

16. W. H. Carothers and J. A. Arivin, J. Am. Chem. Soc., 51, 2560 (1929).

17. T. Akita and S. Oishi, Kogyo Kagaku Zassi, 58, 315 (1935).

18. I. V. Szmeresanyl, K. M. Greger, and E. Makaybodl, J. Polym. Sci., 53, 241 (1961).

19. L. V. Cristobal and P. M. Gilberto A., Polym. Bull., 22, 513 (1989). 